\title{
Time-dependent effectiveness of the intracanal medicaments used for pulp revascularization on the dislocation resistance of MTA
}

Tugba Turk', Beyza Ozisik and Berdan Aydin ${ }^{2 *}$

\begin{abstract}
Background: The aim of the present study was to evaluate the time-dependent effectiveness of the intracanal medicaments used in pulp revascularization on the dislocation resistance of mineral trioxide aggregate (MTA).

Methods: One hundred ninety-two extracted human maxillary incisor teeth were sectioned apically $12 \mathrm{~mm}$ below and coronally $2 \mathrm{~mm}$ above the cemento-enamel junction. Roots were enlarged to size 40 (Protaper F4). Next, Peeso reamers from \#1 to \#5 were used sequentially. Sodium hypochlorite (2.5\%), EDTA (17\%), and distilled water were used in final irrigation. The specimens were randomly divided into four groups $(n=48)$ : Group 1, in which triple antibiotic paste (TAP) (ciprofloxacin + metronidazole + minocycline) was prepared and delivered into the canals using a lentulo spiral; Group 2, in which double antibiotic paste (DAP) (ciprofloxacin + metronidazole) was placed into the canals; Group 3, in which calcium hydroxide paste $(\mathrm{CH})$ (calcium hydroxide + distilled water) was introduced into the roots; and Group 4 (control), in which no medicament was applied into the root canals. Then, the samples were kept in saline solution for 2, 4, and 12 weeks, after which time 16 roots were selected randomly from each group, representing the samples of each time point. After removal of the medicaments, MTA was placed into the coronal third of the roots, and the samples were incubated for 7 days. A push-out test was used to measure the dislocation resistance (DR) of MTA. The data were analyzed using a two-way ANOVA followed by Tukey's pairwise comparisons ( $p=0.05)$.
\end{abstract}

Results: The time factor displayed a significant effect on the DR of MTA $(p<0.05)$. All medicaments resulted in significantly smaller DR values after 12 weeks compared to after 1 week $(p<0.05)$. A significant unfavorable effect of TAP and DAP was observed as early as 2 weeks after the application, while 2 and 4 weeks after the application of $\mathrm{CH}$ there was no effect on the DR of MTA. No significant differences were found between the time points in the control group $(p>0.05)$.

Conclusion: The type and the intracanal duration of medicaments used for pulp revascularization should be chosen carefully to provide maximum antimicrobial effect while creating a favorable environment both for stem cell attachment and MTA adhesion.

Keywords: Regenerative endodontic treatment, Antibiotic pastes, MTA, Intracanal medicaments

\footnotetext{
*Correspondence: berdans@uic.edu

${ }^{2}$ Department of Restorative Dentistry, College of Dentistry, University of Illinois at Chicago, 801 S. Paulina St, Room 531, Chicago, IL 60612, USA Full list of author information is available at the end of the article
} 


\section{Background}

Regenerative endodontic treatment (RET) is a tissue engineering concept specific to pulp and dentin regeneration inside the root canal space of devital teeth [1] in which the pulp tissue is completely removed due to a previous irreversible inflammatory response and microbial invasion. Successful results of RET of immature teeth including control of infection and root development have been shown in many case reports and case series [2-7]. To avoid further weakening of immature teeth, minimal mechanical instrumentation is recommended [8], but a sterile environment is necessary for pulp tissue regeneration in RET $[9,10]$. Thus, disinfection of root canals is attempted only with irrigation solutions and intracanal medicaments $[8,11,12]$. Antibiotic pastes (metronidazole and ciprofloxacin with or without minocycline) and calcium hydroxide $(\mathrm{CH})$ are commonly used medicaments for RET [6, 13-17].

While a 2- to 4-week treatment period is deemed sufficient to obtain the therapeutic effects of antibiotic pastes and $\mathrm{CH}[4-7,14,18-24]$, varying treatment periods from 1 week [3] to several months [5] were used in some case reports. However, alterations of the surface properties and deterioration of the mechanical properties of root canal dentin have been previously demonstrated when endodontic regeneration medicaments were used for long-term periods [25-28].

After the treatment period, MTA was generally placed on the coronal part of the root canal $[4,6,18,21,22,24]$. MTA is a biocompatible, conductive, and inductive calcium silicate-based material that is able to bond to dentin chemically [29]. It is reported that pretreatment of dentin either with irrigants or medicaments may influence the bond strength of MTA [30, 31]. Bond strength is an important factor since teeth are exposed to occlusal and procedural forces that might dislodge the MTA after its placement [32-34]. Recently, Topcuoglu et al. [31] reported that the application of medicaments used in regenerative endodontics for 3 weeks affects the bond strength of MTA placed in root canal dentin. However, the effect of the intracanal duration of medicaments on the dislocation resistance (DR) of MTA has not yet been evaluated.

Therefore, the aim of the present study was to evaluate the time-dependent effectiveness of the intracanal medicaments used in pulp revascularization on the DR of MTA.

\section{Methods}

The study protocol was approved by the Ethics Committee of Ege University (Protocol No. 15-1/9) and written informed consent form was obtained from each patient. One hundred ninety-two human maxillary incisor teeth with a single straight root canal, extracted in Department of Oral \& Maxillofacial Surgery, were collected for this study.
Reasons for extraction were periodontal diseases, such as insufficient periodontal support. The intact teeth were stored in thymol solution (0.1\%) for up to 3 months, observed carefully under 20x magnification, and excluded if resorption, caries, cracks, or fractures were detected.

Buccolingual and mesiodistal dimensions of teeth at the cemento-enamel junction were measured with a digital caliper (Mitutoyo, Tokyo, Japan) to provide standardization, and the mean mesiodistal and buccolingual dimensions were obtained. Thereafter, teeth deviating $20 \%$ in their dimensions compared to the standard values were excluded.

\section{Sample preparation}

Teeth were sectioned apically $12 \mathrm{~mm}$ below and coronally $2 \mathrm{~mm}$ above the cemento-enamel junction with a lowspeed rotary saw (Isomet, Buhler, Lake Bluff, IL, USA). Tissue remnants were removed using a size 20 Hedström file (Dentsply Maillefer, Ballaigues, Switzerland)—samples were instrumented with rotary files (ProTaper, Dentsply, Maillefer, Ballaigues, Switzerland) to standardize the master apical file to be size 40 (F4). Next, Peeso reamers (Maillefer, Ballaigues, Switzerland) from \#1 to \#5 were used sequentially to obtain larger root canals.

Between the uses of each file, the root canals were irrigated with $2 \mathrm{~mL}$ of $2.5 \%$ sodium hypochlorite $(\mathrm{NaOCl})$ (Sigma-Aldrich, St. Louis, MO). Final irrigation was performed using $5 \mathrm{~mL}$ of $2.5 \% \mathrm{NaOCl}(1 \mathrm{~min})$ and $5 \mathrm{~mL}$ of $17 \%$ EDTA (Sigma) $(1 \mathrm{~min})$. Next, the canals were rinsed with sterile distilled water and then dried with paper points (Meta, Metabiomed, Chungbuk, Korea).

\section{Placing intracanal medicaments}

The specimens were randomly divided into four groups: TAP, DAP, $\mathrm{CH}$, and control, with 48 samples in each group. No medicament was used in the control group.

Group 1. TAP paste: 1:1:1 mixture of ciprofloxacin (Bayer, Leverkusen, Germany), metronidazole (Sanofi Aventis, Frankfurt, Germany), and minocycline (Ratiopharm, Ulm, Germany) prepared with sterile distilled water (w/v 3:1), as described by Yassen et al. [35], was delivered into the canals using a lentulo (Dentsply Maillefer, Ballaigues, Switzerland).

Group 2. DAP paste: 1:1 mixture of ciprofloxacin (Bayer) and metronidazole (Sanofi-Aventis) prepared with sterile distilled water (w/v 2.5:1) was delivered into the canals as described previously.

Group 3. $\mathrm{CH}$ paste prepared by mixing calcium hydroxide powder $\left(\mathrm{Ca}(\mathrm{OH})_{2}\right.$, Merck, Darmstadt, Germany) with sterile distilled water (w/v 2:1) was placed into the root canals as described previously. 
The apical root canal orifices were sealed with modeling wax (Dentsply DeTrey, Bois Colombes, France), and the coronal orifices were sealed with glass ionomer cement (Fuji, GC, Tokyo, Japan), including the control group samples $(n=48)$. However, no medicament was applied in the root canals of the control group. All samples were kept in saline solution, which was replenished every 7 days to avoid dehydration throughout the evaluation period, which lasted up to 12 weeks. After 2, 4, and 12 weeks, 16 teeth were selected randomly from each group, representing the samples of each time point. At the end of the incubation period, the temporary filling material was removed with a size 3 round bur (Dentsply Maillefer) under water cooling, followed by the removal of TAP, DAP, and $\mathrm{CH}$ using $2 \mathrm{~mL}$ of $2.5 \% \mathrm{NaOCl}$ and $17 \%$ EDTA. The root canals were then dried using absorbent paper points.

MTA (ProRoot, Dentsply Tulsa Dental, Tulsa, OK) was prepared in accordance with the manufacturer's instructions and placed $4 \mathrm{~mm}$ deep into the coronal third of the roots with an amalgam carrier having a $4 \mathrm{~mm}$ long chamber. Also, a saline-moistened cotton pellet was placed on top of the MTA to accelerate its homogenous setting. After the radiographic control of MTA placement, the samples were stored for a week at $37{ }^{\circ} \mathrm{C}$ at $100 \%$ humidity to allow the setting of the MTA completely.

\section{Push-out test}

After the completion of the storage periods of 2, 4, and 12 weeks, the coronal region of each root was horizontally sectioned to obtain a single slice from each root using an Isomet saw (Buehler, Lake Bluff, IL) under water cooling. Slice thickness was adjusted to $1 \mathrm{~mm} \pm 0.1 \mathrm{~mm}$ utilizing a digital caliper (Mitoyo, Tokyo, Japan), while the root canal space was filled with cement material (MTA). Next, a $1.2 \mathrm{~mm}$ diameter test-tip was positioned over the cement so that it touched only the MTA and did not stress the root canal walls.

The force was applied at a crosshead speed of $1 \mathrm{~mm} / \mathrm{min}$ using a universal testing machine (AGS-X, Schimadzu Co, Kyoto, Japan) until failure occurred. The force $(\mathrm{N})$ required to dislocate the MTA was recorded in Newtons. To express the push-out bond strength in $\mathrm{MPa}$, the load at failure $(\mathrm{N})$ was divided by the area of the adhesion surface, calculated by the following formula: $2 \pi \mathrm{r} \times \mathrm{h}$, where $\pi$ is the constant $3.14, \mathrm{r}$ is the root canal radius, and $\mathrm{h}$ is the thickness of the root slice in millimeters.

\section{Statistical analysis}

The effects of the type of medicament used and the duration of the medicament treatment on the DR of MTA were examined using a two-way ANOVA followed by Tukey's pairwise comparisons. A $95 \%$ confidence interval was applied to determine statistical significance.

\section{Results}

Mean DR values (MPa) after the push-out tests are shown in Table 1. No significant difference was found between the control group at all time-points $(p>0.05)$. The time factor displayed a significant effect on the DR of some experimental groups; prolonged treatment time caused a decrease in DR values. All medicaments resulted in significantly smaller DR values after 12 weeks compared to a 2 -week treatment time $(p<0.05)$. The 12-week treated samples in the TAP, DAP, and $\mathrm{CH}$ groups had significantly smaller DR values compared to the control group $(p<0.05)$. The 2 - and 4 -week-treated samples in the TAP and DAP groups had significantly smaller DR values compared to the control group. There were no statistically significant differences between the control and $\mathrm{CH}$ treated groups with 2- and 4-week treatment periods $(p>0.05)$. Within the experimental groups, the DAP group had the smallest DR values while the $\mathrm{CH}$ group had the highest.

\section{Discussion}

Since its introduction, MTA has been regarded as an ideal material for many dental applications such as pulp capping, repair of perforations, apexification, and lately in RET $[29,32]$. In addition to its biological impacts on tissue healing and regeneration, the DR of MTA should be satisfactory [30, 32, 34, 36] since the DR of such materials is one of the factors that affect sealing ability [30].

MTA is subjected to forces that arise during restorative procedures or mastication when it is placed into the coronal part of the root canal $[31,37]$. The push-out test has been shown to be a reliable method for evaluating the DR of materials [38], and it is utilized in many studies $[31,33,37,39]$. The dentin bonding strength of MTA has been previously evaluated while considering modifications in organic and inorganic dentin compositions that affect the DR of MTA. DR might be influenced by MTA thickness, humidity of the surrounding tissues, evaluation time, alkaline $\mathrm{pH}$ of the environment, and physical properties of the contacting dentin surface [30, 31, 37, 39]. Evaluation of the DR of MTA has become crucial as the dentin surface of the root canal is exposed

Table 1 Mean DR values of groups
\begin{tabular}{llll}
\hline Group & Mean \pm SD $(\mathrm{MPa})$ \\
\cline { 2 - 4 } & 2-week $(n=18)$ & 4-week $(n=18)$ & 12-week $(n=18)$ \\
\hline TAP & $5.19 \pm 0.79^{\mathrm{a}, \mathrm{c}}$ & $4.47 \pm 0.67^{\mathrm{a}, \mathrm{b}, \mathrm{d}}$ & $2.98 \pm 0.84^{\mathrm{a}}$ \\
DAP & $4.90 \pm 0.69^{\mathrm{a}, \mathrm{b}, \mathrm{d}}$ & $4.21 \pm 0.76^{\mathrm{a}, \mathrm{b}, \mathrm{d}}$ & $2.94 \pm 1.01^{\mathrm{a}}$ \\
$\mathrm{CH}$ & $5.64 \pm 0.59^{\mathrm{d}}$ & $5.59 \pm 0.66^{\mathrm{d}}$ & $3.53 \pm 0.99^{\mathrm{a}}$ \\
Control & $5.70 \pm 0.68$ & $5.6 \pm 0.51$ & $5.54 \pm 0.68$
\end{tabular}

${ }^{\mathrm{a} S i g n i f i c a n t ~ d i f f e r e n c e ~ w i t h ~ c o n t r o l ~ g r o u p ~}$

${ }^{\mathrm{b}}$ Significant difference with $\mathrm{CH}$ group

'Significant difference with 4 and 12-week

${ }^{\mathrm{d}}$ Significant difference with 12-week 
to various irrigation solutions and intracanal medicaments, which may alter its chemical and mechanical properties during pulp revascularization procedures or conventional endodontic treatment. Recently, the medicaments used in pulp revascularization were evaluated in regard to their influence on the DR of MTA placed into the root canal dentin. It was found that the application of DAP reduced the DR of MTA, whereas TAP and $\mathrm{CH}$ did not affect the DR after a 3-week period [31]. However, according to the results of the present study, it is noteworthy to mention that DR was significantly affected when TAP intracanal medicament was kept longer than 2 weeks and the $\mathrm{CH}$ intracanal medicament was kept in the root canals longer than 4 weeks. Effects of medicaments on the DR of MTA were compared based on the various treatment periods in the previous case reports, which lack consensus in terms of the optimal treatment period for pulp revascularization. According to the results of the present study, the DR of MTA was influenced by the use of different type of medicaments and various treatment time periods. Antibiotic pastes seemed to affect the DR of MTA in an undesirable manner. The use of DAP decreased the DR in 2 weeks and also caused a further gradual decrease of DR. On the other hand, DR was gradually and significantly decreased when TAP was used in the root canals for 4 to 12 weeks. The effect of TAP and DAP on dentin was evaluated by Yassen et al. [27], who showed that antibiotic pastes have a deteriorating effect that increases in a time-dependent manner due to their acidic nature, which can demineralize dentin. Nonetheless, it was also shown that the application of $\mathrm{CH}$ may cause the collagen degradation of dentin, justifying reduction in the DR of MTA [28]. Recently, significant increases in the surface roughness and alterations in the inorganic phase of dentine like $\mathrm{Ca}$ and $\mathrm{P}$ were demonstrated with the use of TAP, DAP, and $\mathrm{CH}$ on dentine [40, 41].

Demineralization, erosion, and surface roughness of dentin may decrease the initial mechanical adhesion established between MTA and dentin; however, adhesion transforms into a chemical binding by a diffusioncontrolled reaction between the apatite layer of MTA and dentin [29]. The physicochemical interaction of MTA with endodontically prepared root canal dentin was studied by Sarkar et al. [29], who found that MTA leaches some ions, of which $\mathrm{Ca}^{2+}$ is the most abundant. This leads to the formation of an interfacial layer (hydroxyapatite or carbonated apatite), and further examination of this adhesion layer revealed a structure similar in composition to hydroxyapatite that is composed of calcium, phosphorus, and oxygen [29]. The formation of an interfacial layer on MTA is an important factor for such biomaterials because, when MTA comes into close contact with calcified tissues, it forms a chemical bond by means of this interfacial layer [42-44]. It has been speculated that triggering the formation of an interfacial layer between MTA and dentin with medicaments might create a favorable sealing ability as the adhesion and dislodgement resistance of MTA would be enhanced [36, 45, 46]. When phosphate-buffered saline is used as an intracanal dressing after MTA placement, enhanced biomineralization of MTA is observed as the formation of an interfacial layer with tag-like structures [36].

In the present study, adhesion of MTA on $\mathrm{CH}$-treated dentin was greater than the adhesion of MTA on antibiotic-treated dentin at 2 and 4 weeks. Shokounejad et al. [33] suggested the application of non-setting $\mathrm{CH}$ to neutralize the $\mathrm{pH}$ and to increase the DR of MTA prior to the placement of MTA in a low pH environment. One-week $\mathrm{CH}$ treatment was shown to improve the marginal adaptation of the MTA apical plug [47]. This improvement was attributed to the conversion of calcium hydroxide to calcium carbonate or the reaction of MTA with residual calcium hydroxide. Thus, in the current study, the favorable results in the $\mathrm{CH}$-treated group after 2 to 4 weeks may be related to the $\mathrm{Ca}^{2+}$ ions supplied by the residual $\mathrm{CH}$, a phenomenon that has been previously mentioned to explain the improved adhesion of MTA.

A study compared the performance of $\mathrm{CH}$ and TAP removal from root canals, demonstrating that the residues of $\mathrm{CH}$ were distributed rather superficially and contained a smaller amount of material [48]. On the other hand, TAP appeared to have greater retention and deeper penetration; thus, it was more difficult to remove. However, while residual TAP may lead to demineralization of dentin via decreasing the $\mathrm{pH}$, it may also chelate the calcium in dentin, which is reported to be significant in establishing the adhesion of MTA on dentin [27, 33, 49].

$\mathrm{CH}$ caused a significant decrease of the DR of MTA after 12 weeks of treatment. However, 2- and 4-week applications did not exhibit such an effect, indicating the safety of short-term $\mathrm{CH}$ use. The undesired effects of long-term $\mathrm{CH}$ application on the mechanical properties of dentin have been reported by several researchers $[28,50,51]$. The effect of TAP, DAP, and $\mathrm{CH}$ on fracture resistance and microhardness of root canal dentin was investigated, and the longevity of the treatment time was found to have a significant jeopardizing effect on both microhardness and the fracture resistance of roots [28]. Moreover, all type of medicaments significantly decreased the fracture resistance of roots after a 3-month period compared to 1-week application. The application of antibiotic paste significantly decreased the microhardness of dentin after 1- or 3-month periods, whereas 1-week application did not. $\mathrm{CH}$ increased the microhardness of dentin in all treatment periods. Therefore, 
short-term use of the root canal medicaments is suggested to prevent further weakening of the immature root structures. However, root cylinders were left empty after placing the medicaments, and MTA was not used in latter study. Thus, no interpretation can be drawn from their results regarding the DR of MTA.

\section{Conclusions}

All medicaments decreased the DR of MTA after a 12-week application period. However, a significant decreasing effect of TAP and DAP was observed as early as 4 weeks, while 2- and 4-week application of $\mathrm{CH}$ did not effect the DR of MTA. The type and the treatment time of medicaments kept in root canals used for pulp revascularization should be optimized to provide maximum antimicrobial effect while creating a favorable environment both for stem cell attachment and MTA adhesion.

\section{Abbreviations}

MTA: Mineral trioxide aggregate; DR: Dislocation resistance; TAP: Triple antibiotic paste; DAP: Double antibiotic paste; $\mathrm{CH}$ : Calcium hydroxide; EDTA: Ethylene diamine tetraacetic acid; $\mathrm{NaOCl}$ : Sodium hypochlorite; mL: Mililiter; MPa: Megapascal.

\section{Competing interests}

The authors declare that they have no competing interests.

\section{Authors' contributions}

$\Pi$, BA conceived the study, $\Pi$ and $\mathrm{BO}$ carried out all experiments. $\Pi$ and BA drafted the paper. All authors revised and agreed on the final draft. All authors read and approved the final manuscript.

\section{Author details}

'Department of Endodontology, Ege University, School of Dentistry, Izmir, Turkey. ${ }^{2}$ Department of Restorative Dentistry, College of Dentistry, University of Illinois at Chicago, 801 S. Paulina St, Room 531, Chicago, IL 60612, USA.

Received: 26 May 2015 Accepted: 15 October 2015

Published online: 23 October 2015

\section{References}

1. Nakashima M, Huang GT. Pulp and dentin regeneration. In: Huang GT, Thesleff I, editors. Stem cells in craniofacial development and regeneration. Hoboken: Wiley-Blackwell; 2013.

2. Shah N, Logani A, Bhaskar U, Aggarwal V. Efficacy of revascularization to induce apexification/apexogensis in infected, nonvital, immature teeth: a pilot clinical study. J Endod. 2008;34:919-25.

3. Jung IY, Lee SJ, Hargreaves KM. Biologically based treatment of immature permanent teeth with pulpal necrosis: a case series. J Endod. 2008;34:876-87.

4. Cotti E, Mereu M, Lusso D. Regenerative treatment of an immature, traumatized tooth with apical periodontitis: report of a case. J Endod. 2008:34:611-6.

5. Chueh LH, Ho YC, Kuo TC, Lai WH, Chen YH, Chiang CP. Regenerative endodontic treatment for necrotic immature permanent teeth. J Endod. 2009;35:160-4

6. Petrino JA, Boda KK, Shambarger S, Bowles WR, McClanahan SB. Challenges in regenerative endodontics: a case series. J Endod. 2010;36:536-41.

7. Torabinejad M, Turman M. Revitalization of tooth with necrotic pulp and open apex by using platelet-rich plasma: a case report. J Endod. 2011;37:265-8.

8. Fouad AF, Verma P. Healing after Regenerative Procedures with and without Pulpal Infection. J Endod. 2014;40:S58-64.

9. Fouad AF. The microbial challenge to pulp regeneration. Adv Dent Res. 2011;23:285-9.
10. Lin LM, Ricucci D, Huang GT. Regeneration of the dentine-pulp complex with revitalization/revascularization therapy: challenges and hopes. Int Endod J. 2014;47:713-24.

11. Wigler R, Kaufman AY, Lin S, Steinbock N, Hazan-Molina H, Torneck CD Revascularization: a treatment for permanent teeth with necrotic pulp and incomplete root development. J Endod. 2013;39:319-26.

12. Law AS. Considerations for regeneration procedures. J Endod. 2013;39:S44-56.

13. Lovelace TW, Henry MA, Hargreaves KM, Diogenes A. Evaluation of the delivery of mesenchymal stem cells into the root canal space of necrotic immature teeth after clinical regenerative endodontic procedure. J Endod. 2011;37:133-8.

14. Cehreli ZC, Isbitiren B, Sara S, Erbas G. Regenerative endodontic treatment (revascularization) of immature necrotic molars medicated with calcium hydroxide: a case series. J Endod. 2011;37:1327-30.

15. Miller EK, Lee JY, Tawil PZ, Teixeira FB, Vann WF Jr. Emerging therapies for the management of traumatized immature permanenet incisors. Pediatr Dent. 2012;34:66-9.

16. Bezgin T, Yilmaz AD, Celik BN, Sonmez H. Concentrated platelet rich plasma used in root canal revascularization; 2 case reports. Int Endod J. 2014;47:41-9.

17. Hargreaves KM, Diogenes A, Teixeira FB. Paradigm lost: a perspective on the design and interpretation of regenerative endodontic research. J Endod. 2014;40:565-9.

18. Banchs F, Trope M. Revascularization of immature permanent teeth with apical periodontitis: new treatment protocol? J Endod. 2004;30:196-200.

19. Ding RY, Cheung GS, Chen J, Yin XZ, Wang QQ, Zhang CF. Pulp revascularization of immature teeth with apical periodontitis: a clinical study. J Endod. 2009;35:745-9.

20. Reynolds K, Johnson JD, Cohenca N. Pulp revascularization of necrotic bilateral bicuspids using a modified novel technique to eliminate potential coronal discolouration: a case report. Int Endod J. 2009;42:84-92.

21. Nosrat A, Seifi A, Asgary S. Regenerative endodontic treatment (revascularization) for necrotic immature permanent molars: a review and report of two cases with a new biomaterial. J Endod. 2011;37:562-7.

22. Lenzi $R$, Trope M. Revitalization procedures in two traumatized incisors with different biological outcomes. J Endod. 2012;38:411-4.

23. Jeeruphan T, Jantarat J, Yanpiset K, Suwannapan L, Khewsawai P, Hargreaves KM. Mahidol study 1: Comparison of radiographic and survival outcomes of immature teeth treated with either regenerative endodontic or apexification methods: a retrospective study. J Endod. 2012;38:1330-6.

24. Chen MY, Chen KL, Chen CA, Tayebaty F, Rosenberg PA, Lin LM. Responses of immature permanent teeth with infected necrotic pulp tissue and apical periodontitis/abscess to revascularization procedures. Int Endod J. 2011:45:294-305

25. Marending M, Stark WJ, Brunner TJ, Fischer J, Zehnder M. Comparative assessment of time-related bioactive glass and calcium hydroxide effects on mechanical properties of human root dentin. Dent Traumatol. 2009;25:126-9.

26. Sahebi S, Moazami F, Abbott P. The effects of short-term calcium hydroxide application on the strength of dentine. Dent Traumatol. 2010;26:43-6.

27. Yassen GH, Chu TM, Eckert G, Platt JA. Effect of medicaments used in endodontic regeneration technique on the chemical structure of human immature radicular dentin: an in vitro study. J Endod. 2013;39:269-73.

28. Yassen GH, Vail MM, Chu TG, Platt JA. The effect of medicaments used in endodontic regeneration on root fracture and microhardness of radicular dentine. Int Endod J. 2013:46:688-95.

29. Sarkar NK, Caicedo R, Ritwik P, Moiseyeva R, Kawashima I. Physicochemical basis of the biologic properties of mineral trioxide aggregate. J Endod. 2005;31:97-100.

30. El-Ma'aita AM, Qualtrough AJ, Watts DC. The effect of smear layer on the push-out bond strength of root canal calcium silicate cements. Dent Mater. 2013;29(7):797-80.

31. Topçuoğlu HS, Arslan H, Akçay M, Saygili G, Cakici F, Topçuoğlu G. The effect of medicaments used in endodontic regeneration technique on the dislocation resistance of mineral trioxide aggregate to root Canal dentine. Int Endod J. 2014;46:688-95.

32. Parirokh M, Torabinejad M. Mineral trioxide aggregate: a comprehensive literature review-Part I: chemical, physical, and antibacterial properties. J Endod. 2010;36:16-27.

33. Shokouhinejad N, Nekoofar MH, Iravani A, Kharrazifard MJ, Dummer PM. Effect of acidic environment on the push-out bond strength of mineral trioxide aggregate. J Endod. 2010;36:871-4. 
34. Guneser MB, Akbulut MB, Eldeniz AU. Effect of various endodontic irrigants on the push-out bond strength of biodentine and conventional root perforation repair materials. J Endod. 2013;39:380-4.

35. Yassen GH, Chu TM, Gallant MA, Allen MR, Vail MM, Murray PE, et al. A nove approach to evaluate the effect of medicaments used in endodontic regeneration on root canal surface indentation. Clin Oral Investig. 2014;18:1569-75.

36. Reyes-Carmona JF, Felippe MS, Felippe WT. The biomineralization ability of mineral trioxide aggregate and Portland cement on dentin enhances the push-out strength. J Endod. 2010;36:286-91.

37. Hasheem AA, Wannes Amin SA. The Effect of Acidity on Dislodgment Resistance of Mineral Trioxide Aggregate and Bioaggregate in Furcation Perforations. An In vitro Comparative Study. 2012;38:245-9.

38. Goracci C, Tavares AU, Fabianelli A, Monticelli F, Raffaelli O, Cardoso PC, et al. The adhesion between fiber posts and root canal walls: comparison between microtensile and push-out bond strength measurements. Eur J Oral Sci. 2004;112:353-61.

39. Saghiri MA, Shokouhinejad N, Lotfi M, Aminsobhani M, Saghiri AM. Push-out bond strength of mineral trioxide aggregate in the presence of alkaline $\mathrm{pH}$. J Endod. 2010;36:1856-9.

40. Yassen GH, Sabrah AH, Eckert GJ, Platt JA. Effect of different endodontic regeneration protocols on wettability, roughness, and chemical composition of surface dentin. J Endod. 2015;41:956-60.

41. Nerness AZ, Ehrlich Y, Spolnik K, Platt JA, Yassen GH. Effect of triple antibiotic paste with or without ethylenediaminetetraacetic acid on surface loss and surface roughness of radicular dentine. Odontology. 2015. doi:10.1007/s10266-014-0191-0.

42. Kokubo T. Surface chemistry of bioactive glass-ceramics. J Non-Cryst Solids. 1990;120:138-51.

43. Kokubo T. Bioactive glass ceramics: properties and applications. Biomaterials. 1991;12:155-63.

44. Yuan H, Li Y, de Bruijn JD, de Groot K, Zhang X. Tissue responses of calcium phosphate cement: a study in dogs. Biomaterials. 2000;21:1283-90.

45. Hachmeister DR, Schindler WG, Walker 3rd WA, Thomas DD. The sealing ability and retention characteristics of mineral trioxide aggregate in a mode of apexification. J Endod. 2002;28:386-90.

46. Reyes-Carmona JF, Felippe MS, Felippe WT. Biomineralization ability and interaction of mineral trioxide aggregate and white portland cement with dentin in a phosphate-containing fluid. J Endod. 2009:35:731-6.

47. Bidar M, Disfani R, Gharagozloo S, Khoynezhad S, Rouhani A. Medication with calcium hydroxide improved marginal adaptation of mineral trioxide aggregate apical barrier. J Endod. 2010;36:1679-82.

48. Berkhoff JA, Chen PB, Teixeira FB, Diogenes A. Evaluation of triple antibiotic paste removal by different irrigation procedures. J Endod. 2014;40:1172-7.

49. Minabe M, Takeuchi $\mathrm{K}$, Kumada H, Umemoto T. The effect of root conditioning with minocycline $\mathrm{HCl}$ in removing endotoxin from the roots of periodontally-involved teeth. J Periodontol. 1994:65:387-92.

50. Andreasen JO, Munksgaard EC, Bakland LK. Comparison of fracture resistance in root canals of immature sheep teeth after filling with calcium hydroxide or MTA. Dent Traumatol. 2006;22:154-6.

51. Hatibovic-Kofman S, Raimundo L, Zheng L, Chong L, Friedman M, Andreasen JO. Fracture resistance and histological findings of immature teeth treated with mineral trioxide aggregate. Dent Traumatol. 2008;24:272-6.

\section{Submit your next manuscript to BioMed Central and take full advantage of:}

- Convenient online submission

- Thorough peer review

- No space constraints or color figure charges

- Immediate publication on acceptance

- Inclusion in PubMed, CAS, Scopus and Google Scholar

- Research which is freely available for redistribution 